\title{
Endothelial Function in Patients with Subclinical Hypothyroidism: A Meta-Analysis
}

\author{
Authors \\ Ningning Gong ${ }^{1}$, Cuixia Gao², Xuedi Chen¹, Yuan Fang1', Limin Tian¹, 3,4
}

\author{
Affiliations \\ 1 Department of Endocrinology, Gansu Provincial Hospital, \\ Gansu, China \\ 2 Department of Ultrasonic Diagnosis, Gansu Provincial \\ Hospital, Gansu, China \\ 3 Lanzhou University School of Medicine, Dong Gang West \\ Road, Gansu, China \\ 4 Clinical Research Center for Metabolic Diseases, Gansu \\ Province, China
}

Key words

endothelial function, subclinical hypothyroidism, meta-analysis

received $\quad 28.10 .2018$

accepted $\quad 12.09 .2019$

\author{
Bibliography \\ DOI https://doi.org/10.1055/a-1018-9564 \\ Horm Metab Res 2019; 51: 691-702 \\ (c) Georg Thieme Verlag KG Stuttgart · New York \\ ISSN 0018-5043 \\ Correspondence \\ Limin Tian \\ Department of Endocrinology \\ Gansu Provincial Hospital \\ Dong Gang West Road \\ Lanzhou \\ 730000 Gansu \\ China \\ Tel.: + 86 15293184257, Fax: + 869316266957 \\ tlm6666@sina.com
}

\begin{abstract}
Supplementary Material: for this article is available online at http://www.thieme-connect.de/products.
\end{abstract}

\section{ABSTRACT}

The purpose of this meta-analysis was to determine whether patients with subclinical hypothyroidism $(\mathrm{SCH})$ have impaired endothelial function, which is assessed by carotid intima-media thickness (C-IMT) and flow-mediated dilatation (FMD) of brachial artery. PubMed, Embase and Cochrane Library databases and the key studies references were searched in our study, prior to July 2017 for all language articles about FMD or C-IMT in $\mathrm{SCH}$ and euthyroid subjects. Two authors screened documents and extracted data by pre-established standard independently. The pooled estimate for continuous data was calculated using random-effects models. Statistical heterogeneity was evaluated using $\mathrm{I}^{2}$ statistics. Subgroup analyses were conducted to assess the robustness of the meta-analysis. Publication bias was examined with funnel plot analysis and Egger's test. In this meta-analysis, 10 studies with 760 subjects are related to $\mathrm{FMD}$ with $\mathrm{SCH}$ and 23 studies with 1521 subjects are related to $\mathrm{C}-\mathrm{IMT}$ with $\mathrm{SCH}$. The pooled estimate of the weighted mean difference (WMD) has revealed that SCH correlated with increased C-IMT [WMD 0.069 mm; $95 \% \mathrm{Cl}$ (0.042, 0.095); $\mathrm{p}<0.001$ ] and decreased FMD [WMD $-1.848 \%$; $95 \% \mathrm{Cl}$ $(-2.298,-1.399) ; \mathrm{p}<0.001]$ with high heterogeneity. Compared with EU controls, SCH was also associated with an increased diastolic blood pressure (DBP), systolic blood pressure (SBP), triglyceride (TG), total cholesterol (TC) levels, and low density lipoprotein cholesterol (LDL-C). This meta-analysis demonstrates that $\mathrm{SCH}$ is associated with endothelial dysfunction, which may relate with increased thyroid-stimulating hormone (TSH). Hypertension and dyslipidemia may play a crucial part in the development of endothelial dysfunction.

\section{Introduction}

Subclinical hypothyroidism ( $\mathrm{SCH}$ ) is defined by elevated serum thyroid-stimulating hormone (TSH) with normal thyroid hormones levels. The prevalence of $\mathrm{SCH}$ is $5-10 \%$, being more frequent with increased age and higher incidence in women [1-3]; the prevalence of $\mathrm{SCH}$ is up to $20 \%$ in women older than $60 \mathrm{yrs}$ [1]. Recently, some studies have shown that $\mathrm{SCH}$ associated with systolic dysfunction [4], heart failure [5], coronary heart disease and other chronic heart diseases [6, 7]. In addition, the relationship between $\mathrm{SCH}$ and the risk for atherosclerosis (AS) has also been reported in large population-based studies [8,9]. Moreover, multiple lines of evidence have shown that endothelial dysfunction [10] and dyslipidemia [11] play central roles in the development of AS. The relationships between $\mathrm{SCH}$ with endothelial dysfunction and dyslipidemia have also been reported in some studies $[12,13]$.

Endothelial dysfunction is an early step for the development of AS and cardiovascular disease (CVD), which is mostly assessed by flow-mediated dilatation (FMD) and carotid intima-media thickness 
(C-IMT) of brachial artery $[14,15]$. A meta-analysis including 14 cohort studies with 5547 participants has shown that $1 \%$ decrease and 1 -standard deviation (SD) decrease in FMD was associated with $8 \%$ and $22 \%$ increase in risk of future cardiovascular events, respectively. It does illustrate that the vascular endothelium plays a critical role in various phases of the atherosclerotic disease process [16]. Studies have also demonstrated that FMD impaired the vascular, which relates to endothelium-dependent dilatation and increased the risk of AS $[17,18]$. C-IMT, measured using carotid ultrasonography, plays a key role in the process of CVD [19]. A meta-analysis with 37197 participants who were followed up for a mean of 5.5 yrs has shown that the future risk of stroke increased by $13-18 \%$ and the myocardial infarction incidence increased by $10-15 \%$ among the C-IMT increase of $0.1 \mathrm{~mm}$. It shows that the incidence of cardiovascular events is associated with increased C-IMT [20]. In the past twelve yrs, some studies have demonstrated that SCH was associated with endothelial dysfunction which relates to the reduction of FMD and the increase of C-IMT [12, 13, 21-23], but other studies have demonstrated that FMD and C-IMT in SCH patients was not significantly different compared with controls [24-26].

This meta-analysis aims to determine the relationship between SCH and endothelial function by using FMD and C-IMT and to explore the clinical and methodological heterogeneities between studies. In addition, the studies of Gao et al., which prior to November 2011 included 3602 subjects have also revealed that C-IMT increased in patients with SCH compared with controls (the pooled estimate of the weighted mean difference (WMD)was $0.056 \mathrm{~mm}$ ) [27]. But these clinical studies in the definition of SCH are inconsistent and the qualities of these studies are uneven, as well as the results are not consistent. Moreover, only 7 higher-quality studies with 464 subjects were included in this meta-analysis, which does not strongly explain the relationship between SCH and C-IMT. We newly included 16 related documents with 1009 subjects to more effectively illustrate these relations. Simultaneously, diastolic blood pressure (DBP), systolic blood pressure (SBP), triglyceride (TG), total cholesterol (TC), high density lipoprotein cholesterol (HDLC), and low density lipoprotein cholesterol (LDL-C) were also observed in this meta-analysis as important risk factors for AS.

\section{Materials and Methods}

\section{Search strategy}

PubMed, Embase and Cochrane Library databases were searched in this study, prior to July 2017 for all language articles about SCH and FMD \% or C-IMT. Medical Subject Headings (MeSH) terms and free-text words used depended on the database characteristics. The detailed search strategies of each database could be found in the supplementary information $>$ Appendix 1. In addition, we also searched all references of relevant studies and reviews.

\section{Inclusion criteria}

Studies were included by following criteria: 1) Patients with $\mathrm{SCH}$ were defined as elevated serum TSH and normal free thyroid hormones concentrations; 2) C-IMT or FMD brachial artery in subjects both SCH and euthyroidism (EU) groups were detected by high-resolution ultrasound methods; FMD of the brachial artery was calcu- lated as [(hyperemic flow diameter-baseline diameter)/baseline diameter] $\times 100 \%$, where hyperemic flow diameter is the maximal diameter in the brachial artery and baseline diameter is the diameter of the brachial artery before any flow stimulus; 3 ) the evaluated of C-IMT must be within the average of common carotid artery; and 4) high-resolution ultrasonography was used to detect FMD\%.

\section{Exclusion criteria}

Subjects who were taking any drugs that affect the thyroid state or endothelial function were excluded (e. g., antihypertensive agents, acetylsalicylic acid, antihistamines, and multivitamins). Patients with any risk factors of the CVD and some chronic disease, which may affect blood pressure or lipids were excluded (e. g., diabetes mellitus, chronic renal failure, chronic hepatic failure and hypertension). Obese (BMI>30 kg/m²) people and pregnancy women were also excluded. The specific exclusion criteria included in the study are listed $>$ Table 1 .

\section{Data extraction and quality assessment}

Two authors screened documents and extracted data by pre-established standard independently. First, we excluded some studies, which were duplicated in our search result. Then, we excluded those studies, which did not adapt to our research by reading title and abstracts. Also, abstracts of meetings, letters, reviews and other studies, which did not include FMD \% or C-IMT data between $\mathrm{SCH}$ and control subjects were excluded by reading full text. All of studies comparing C-IMT and FMD \% values (mean \pm SD or median (interquartile range)), sample size, proportion of females, TSH value and metabolic parameters in SCH participants with euthyroid subjects were extracted. Additionally, the methodological quality of each study was evaluated with the Newcastle-Ottawa Scale (NOS), which is specifically developed to assess quality of non-randomized observational studies [28]. The scoring system encompasses three major domains, which included selection, comparability, and exposure and eight entries. The resulting score range is between 0 and 9 , a higher score representing a better methodological quality. Literature with a NOS score of less than 8 are excluded as low quality documents.

\section{Statistical analysis}

Stata statistical software version 12.0 (StataCorp, College Station, TX, USA) was used for this meta-analysis. The pooled estimate of the weighted mean difference (WMD) and $95 \% \mathrm{CI}$ for continuous data were calculated using random-effects models [29]. C-IMT and FMD and its $95 \% \mathrm{Cls}$ in $\mathrm{SCH}$ and control groups were illustrated by a forest plot. Heterogeneity was determined by calculating the inconsistency index $\mathrm{I}^{2}$ using the chi-squared test for significance (a $\mathrm{P}$-value $<0.1$ was considered statistically significant) and $\mathrm{I}^{2}$ tests ( $I^{2}>50 \%$ : high heterogeneity; $I^{2}<25 \%$ : low heterogeneity) [30], which are used for determining the percentage of total variation across these studies. We also made subgroup or sensitivity analysis for all studies, including the percent of women as $\geq 82$ or $<82 \%$, TSH values as $\geq 10 \mathrm{mIU} / \mathrm{l}$ or $<10 \mathrm{mIU} / \mathrm{l}$ and ages ( $<20 \mathrm{yrs}, 20-30 \mathrm{yrs}$, 30-40 yrs, 40-50 yrs, and 50-60 yrs). Metabolic parameters (BMI, SBP, DBP, TC, LDL, TG, and HDL) were also calculated and combined in the meta-analysis by WMD and $95 \%$ Cls. Publication bias was assessed using Egger's correlation test method [31]. 


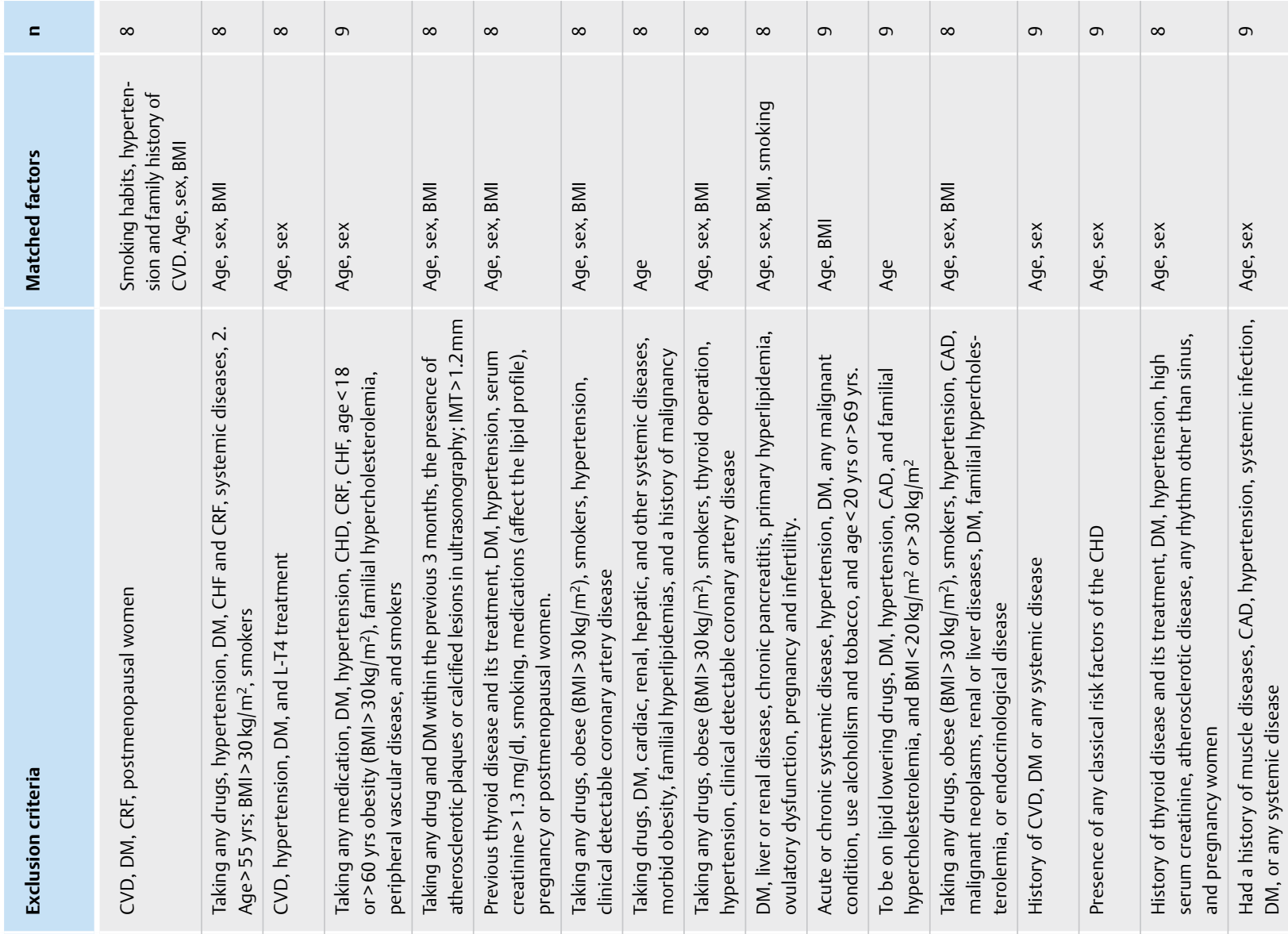

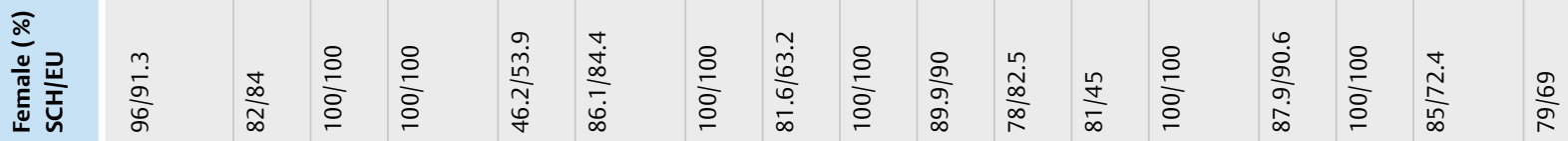

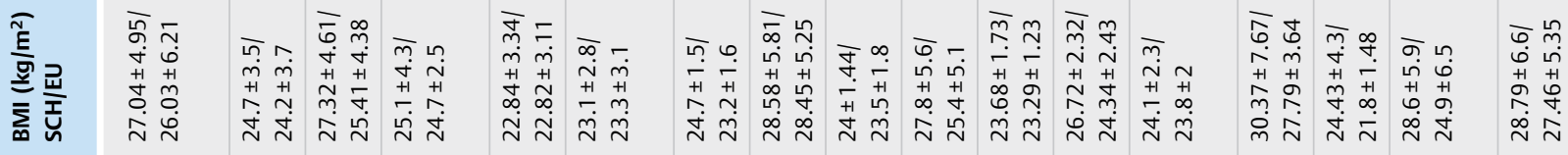

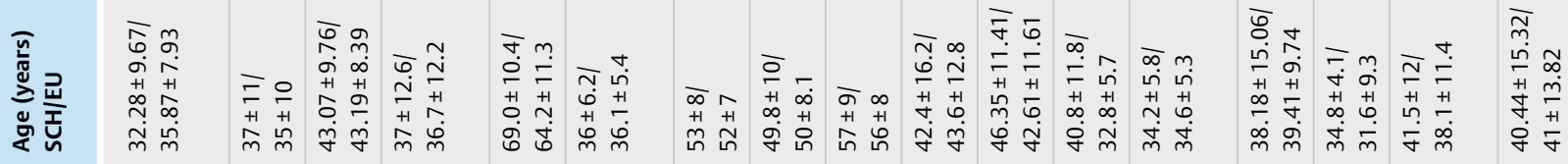

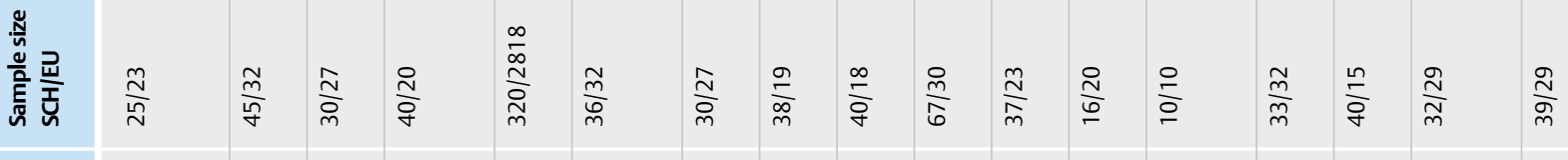

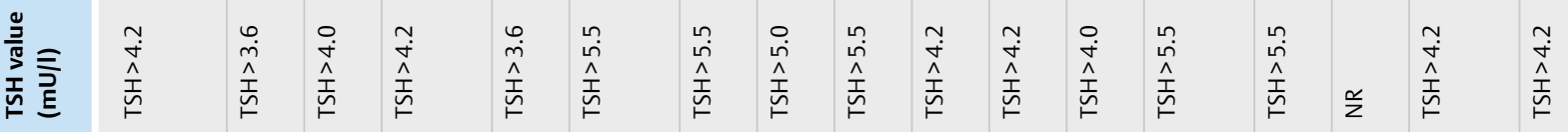

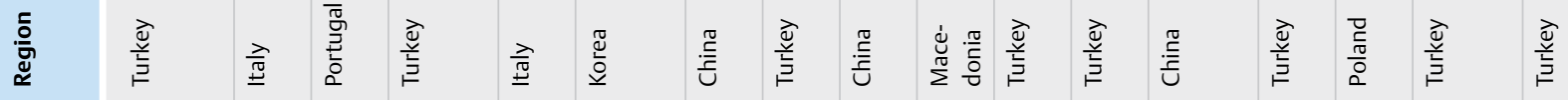

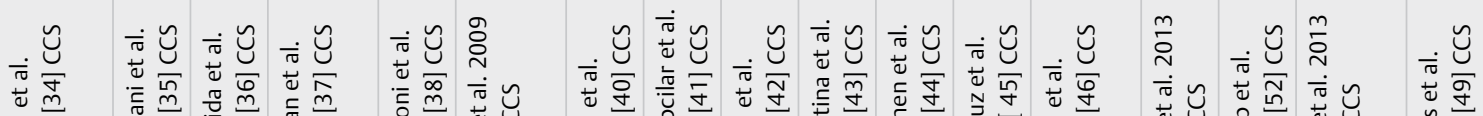

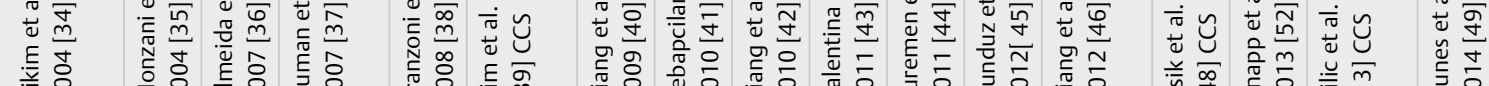

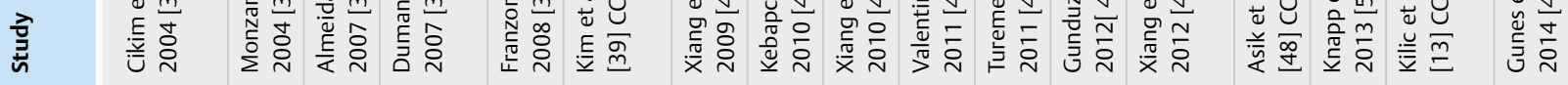




\begin{tabular}{|c|c|c|c|c|c|c|c|c|c|c|c|c|c|}
\hline$=$ & $\infty$ & $\infty$ & $\infty$ & $\infty$ & $\infty$ & $a$ & $\infty$ & $\infty$ & $\infty$ & $\infty$ & $\infty$ & $\infty$ & \\
\hline 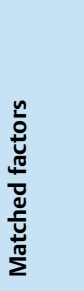 & 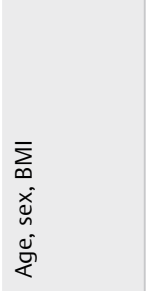 & $\frac{\tilde{c}}{z}$ & 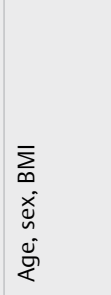 & 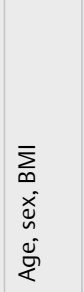 & 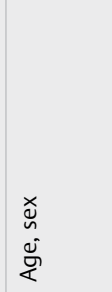 & 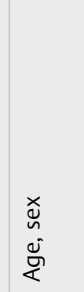 & 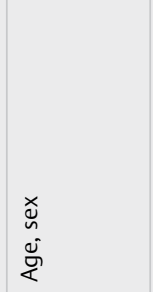 & $\begin{array}{l}\text { 㐅̀ } \\
\text { s. } \\
\text { ș }\end{array}$ & 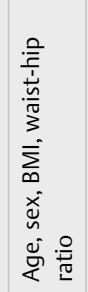 & $\begin{array}{l}\text { 㐅े } \\
\text { s. } \\
\text { ș }\end{array}$ & 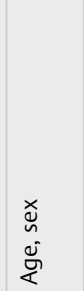 & $\begin{array}{l}\text { 㐅̀ } \\
u \\
\tilde{g}\end{array}$ & 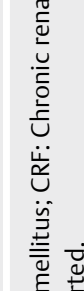 \\
\hline 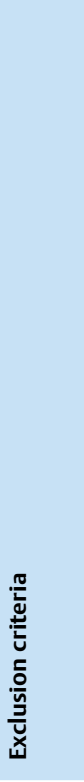 & 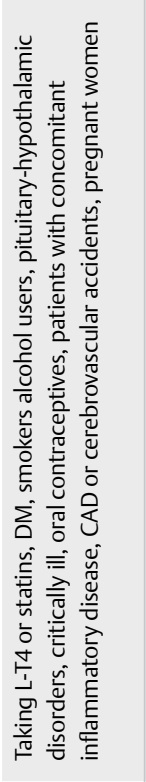 & 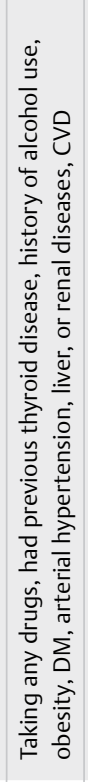 & 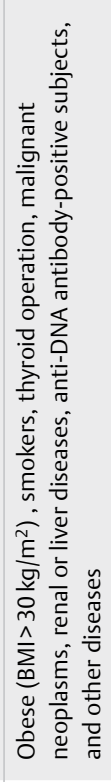 & 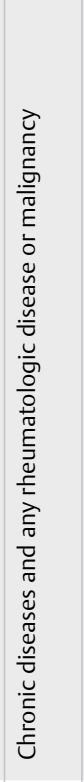 & 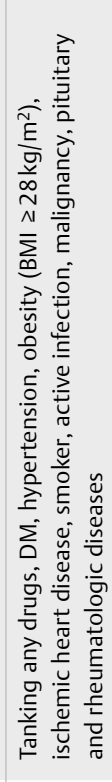 & 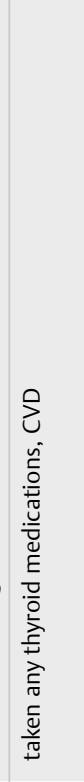 & 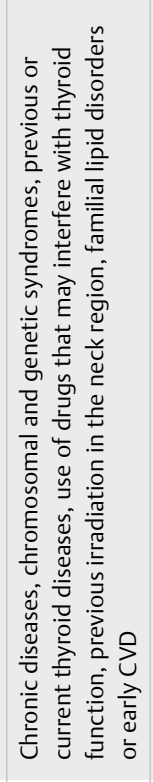 & 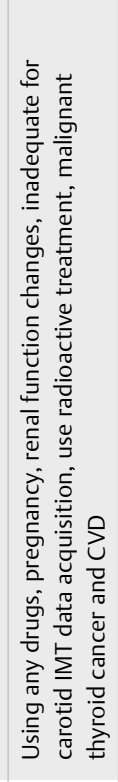 & 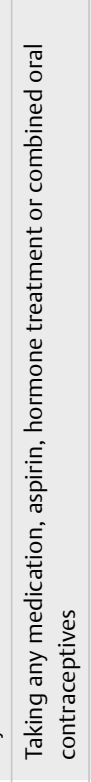 & 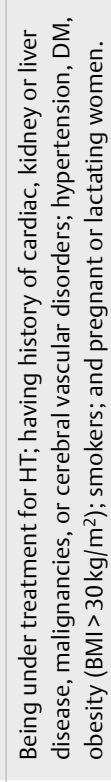 & 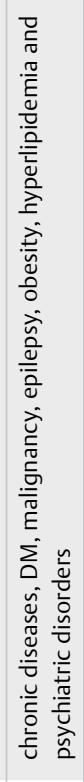 & 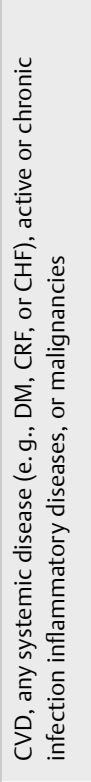 & 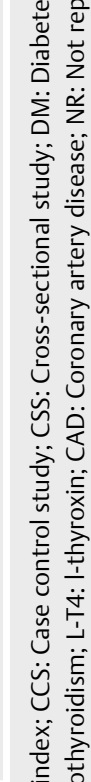 \\
\hline 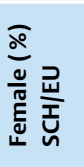 & $\frac{0}{i}$ & 辛 & $\frac{8}{\circ}$ & 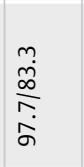 & $\frac{8}{\stackrel{\circ}{n}}$ & 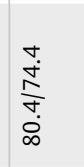 & 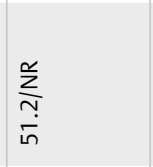 & $\underset{\substack{m \\
\stackrel{n}{N} \\
\infty}}{\infty}$ & 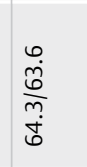 & $\frac{8}{8}$ & 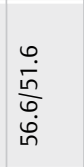 & 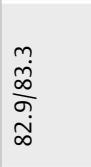 & 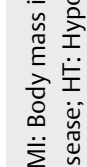 \\
\hline 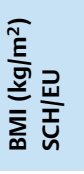 & $\stackrel{\tilde{z}}{z}$ & 兰 & 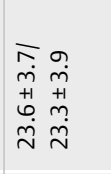 & 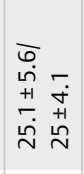 & 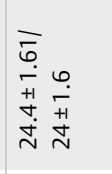 & 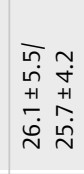 & $\frac{\mathscr{N}}{\mathrm{z}}$ & 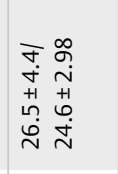 & 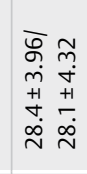 & 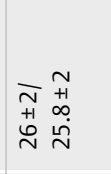 & 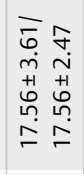 & 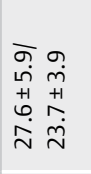 & 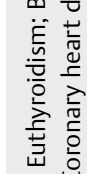 \\
\hline 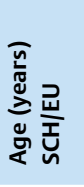 & 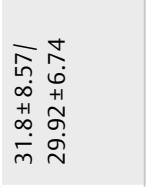 & 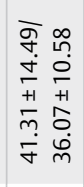 & 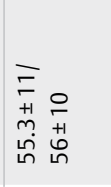 & 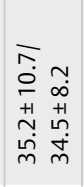 & 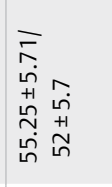 & 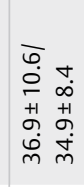 & 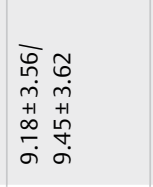 & 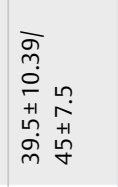 & 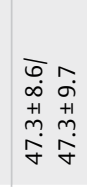 & 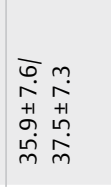 & 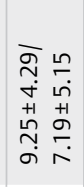 & 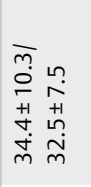 & 产 \\
\hline 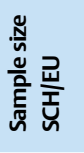 & $\frac{\text { hn }}{\text { in }}$ & $\frac{g}{b}$ & 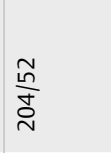 & $\frac{\stackrel{\rho}{m}}{\frac{p}{\gamma}}$ & $\stackrel{\circ}{\frac{0}{i}}$ & 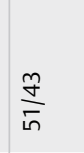 & 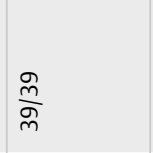 & $\frac{n}{\sigma}$ & $\stackrel{\frac{j}{\infty}}{\sim}$ & $\stackrel{\stackrel{\mathfrak{N}}{\mathfrak{N}}}{\stackrel{n}{N}}$ & $\frac{\bar{m}}{\frac{m}{n}}$ & $\underset{\substack{m \\
m}}{\stackrel{m}{m}}$ & 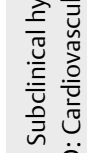 \\
\hline 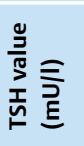 & $\begin{array}{l}\stackrel{0}{\dot{+}} \\
\hat{\Lambda} \\
\stackrel{I}{\Lambda}\end{array}$ & 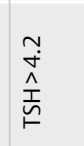 & 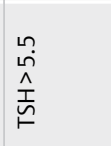 & $\begin{array}{l}\stackrel{0}{\dot{+}} \\
\hat{\Lambda} \\
\stackrel{\Lambda}{⺊}\end{array}$ & 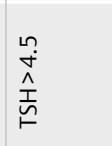 & 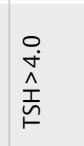 & 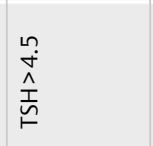 & 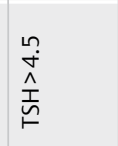 & 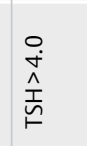 & $\begin{array}{l}\stackrel{0}{\dot{I}} \\
\hat{\Lambda} \\
\hat{\mapsto}\end{array}$ & $\frac{\alpha}{z}$ & $\frac{o}{z}$ & $\begin{array}{l}\breve{d} \\
\ddot{0}\end{array}$ \\
\hline 这 & $\begin{array}{l}\text { 离 } \\
\underline{\underline{\underline{\underline{t}}}}\end{array}$ & 㖣 & 胥 & 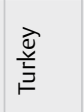 & 胥 & 㖣 & $\bar{I}$ & $\begin{array}{l}\bar{N} \\
\bar{D} \\
\text { D. }\end{array}$ & 苞 & 矛 & 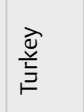 & 㖣 & 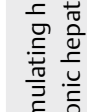 \\
\hline 㟳 & 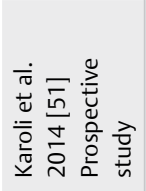 & 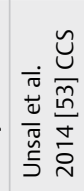 & 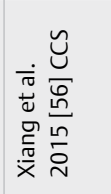 & 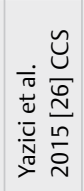 & 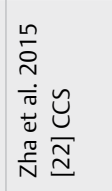 & 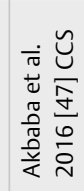 & 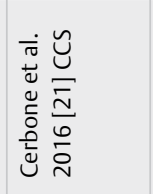 & 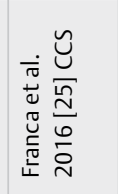 & 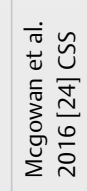 & 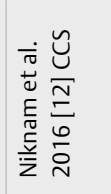 & 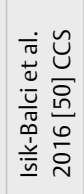 & 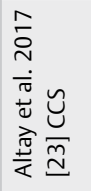 & 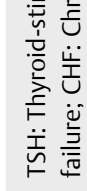 \\
\hline
\end{tabular}




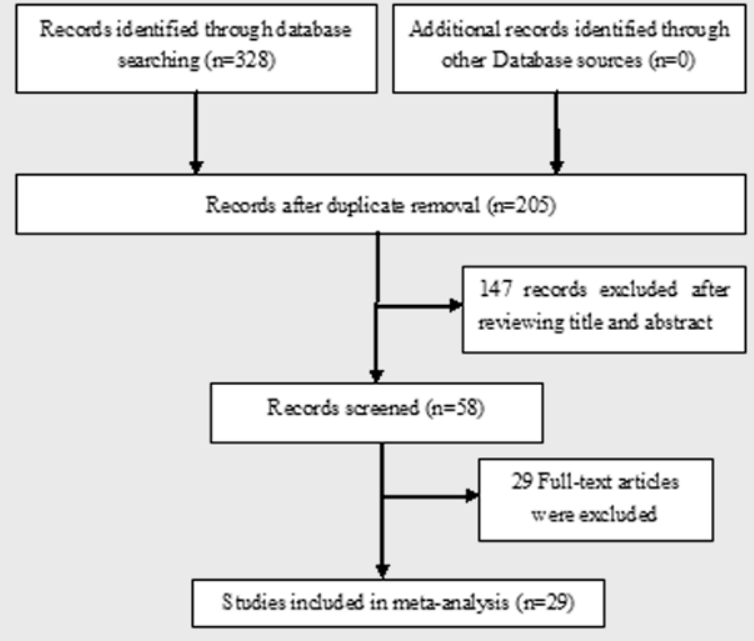

- Fig. 1 Study of selection process.

\section{Results}

\section{Study selection and characteristics}

We achieved 328 studies about SCH and endothelial function or C-IMT or FMD\% in the above electronic resource. Then, 123 studies were excluded by removing duplicates and 147 studies were excluded on the basis of title or abstracts. Also, we excluded abstracts of meetings, letters, reviews, and some researches where FMD \% or C-IMT data between SCH and control subjects were not available. The study of Unal et al.[32] detected only that right C-IMT was excluded. We also excluded a cross-sectional study [33], which did not specify the balance of participants with other chronic diseases that could affect C-IMT (such as diabetes mellitus or hypertension, etc.). Finally, 29 original case control studies [12, 13, 21-26, 34-53, 56] with 2051 patients were included in this meta-analysis ( $\mathbf{F i g . ~ 1 ) . ~}$ The characteristic of these studies is shown in > Table 1. Patient's characteristics and the results of the NOS quality assessment and metabolic parameters in both SCH and control groups are shown in > Table 2 and $>$ Table 3.

\section{Changes of C-IMT and FMD in SCH and EU subjects}

In 29 studies, 23 clinical studies [12, 13, 21-23, 25, 26, 34-39, $41,43,45,47-53$ ] with 1521 patients were included to explore the changes of C-IMT in SCH subjects. The pooled estimate represented a significant increase in C-IMT among subjects with $\mathrm{SCH}$ compared to controls [WMD $0.069 \mathrm{~mm}$; $95 \% \mathrm{Cl}(0.042,0.095)$; $\mathrm{p}<0.001]$. Significant statistical heterogeneity was evident among

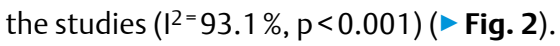

In total, 10 original studies [12, 24, 34, 40, 42, 44, 46, 54-56] with 760 subjects were included to explore the changes of FMD in $\mathrm{SCH}$ subjects. It was demonstrated that FMD significantly decreased in SCH compared with control groups [WMD - 1.848\%; $95 \% \mathrm{Cl}(-2.298,-1.399) ; \mathrm{p}<0.001$ ], with heterogeneity, $\mathrm{I}^{2}=75.5 \%$ ( Fig. 3).

\section{Subgroup analysis}

We conducted a subgroup of women with $\geq 82$ or $<82 \%$ in SCH patients and comparing their C-IMT values with those of EU controls. $\mathrm{C}$-IMT was significantly increased in $\mathrm{SCH}$ with a proportion of women $\geq 82 \%$ [WMD $0.078 \mathrm{~mm} ; 95 \% \mathrm{Cl}(0.034,0.122) ; \mathrm{p}=0.001$ ] and high heterogeneity $\left(\mathrm{I}^{2}=88.8 \%\right)$, but it also increased in subjects with $\mathrm{SCH}$ with a proportion of women < $82 \%$ [WMD $0.061 \mathrm{~mm}$; $95 \% \mathrm{Cl}(0.028,0.093) ; \mathrm{p}<0.001]$ with heterogeneity $\left(I^{2}=93.0 \%\right)$. TSH value and BMI were also conducted as another subgroups analysis. The $\mathrm{C}-\mathrm{IMT}$ in patients with $\mathrm{SCH}$ with $\mathrm{TSH}<10 \mathrm{mIU} / \mathrm{I}$ was statistically increased [WMD $0.060 \mathrm{~mm} ; 95 \% \mathrm{Cl}(0.036,0.084) ; \mathrm{p}<0.001$ ] and the heterogeneity was decreased $\left(I^{2}=81.1 \%\right)$ compared with controls, but there was no significant difference in $\mathrm{SCH}$ with $\mathrm{TSH} \geq 10 \mathrm{mIU} / \mathrm{I}$ [WMD $0.105 \mathrm{~mm}$; $95 \% \mathrm{Cl}(-0.006,0.216)$; $\mathrm{p}=0.064]$ and heterogeneity was $\mathrm{I}^{2}=97.2 \%$. However, C-IMT was significantly higher in SCH patients with $\mathrm{TSH} \geq 10 \mathrm{mIU} / \mathrm{I}$ in WMD as compared to $\mathrm{SCH}$ with $\mathrm{TSH}<10.0 \mathrm{mIU} / \mathrm{I}$ when compared to controls (WMD $0.105 \mathrm{~mm}$ vs. $0.060 \mathrm{~mm}$ ). Subjects with SCH having $\mathrm{BMI}<25 \mathrm{~kg} / \mathrm{m}^{2}$ exhibited higher C-IMT values [WMD $0.145 \mathrm{~mm}$; $95 \% \mathrm{Cl}(0.076,0.213) ; \mathrm{p}<0.001]$ versus SCH patients with $\mathrm{BMI} \geq 25 \mathrm{~kg} / \mathrm{m}^{2}$ [WMD $0.041 \mathrm{~mm} ; 95 \% \mathrm{Cl}(0.013,0.069) ; \mathrm{p}=0.004$ ] than EU controls. We also conducted a subgroup analysis based on age groups. The C-IMT of WMD with $95 \% \mathrm{Cl}$ was [0.188 mm; $(0.122$, $0.253)$; $\mathrm{p}<0.001)$ ] for SCH subjects aged $\leq 50$ to $<60$ yrs and decreased heterogeneity $\left(I^{2}=0\right)$ and $[0.078 \mathrm{~mm} ;(0.038,0.119)$; $\mathrm{p}<0.001$ ) with $\mathrm{I}^{2}=94.3 \%$ for subjects aged $\leq 30$ to $<40$ yrs. However, there are no significant differences in subjects aged $\leq 40$ to $<50$ yrs [WMD $0.037 \mathrm{~mm}$; $95 \% \mathrm{Cl}(-0.008,0.083) ; \mathrm{p}=0.107$ ] with $\mathrm{I}^{2}=72.8 \%$ and aged $<20 \mathrm{yrs}$ [WMD $0.027 \mathrm{~mm} ; 95 \% \mathrm{Cl}(-0.022$, $0.076) ; p=0.279$ ] with $I^{2}=87.4 \%$ compared with EU controls ( Table 3 ).

FMD was significantly decreased in SCH with a proportion of women $\geq 82 \%$ [WMD - 1.801\%; $95 \% \mathrm{Cl}(-2.171,-1.431) ; \mathrm{p}<0.001$ ] and the heterogeneity was $\mathrm{I}^{2}=73.2 \%$ and in $\mathrm{SCH}$ with a proportion of women<90\% [WMD - 2.144\%; $95 \% \mathrm{Cl}(-4.022,-0.267) ; \mathrm{p}=0.025$ ] with heterogeneity $\mathrm{I}^{2}=81.4 \%$. The FMD in patients with $\mathrm{SCH}$ with $\mathrm{TSH} \geq 10 \mathrm{mIU} / \mathrm{I}$ was statistically decreased [WMD $-3.400 \mathrm{~mm} ; 95 \% \mathrm{Cl}$ $(-5.685,-1.115) ; \mathrm{p}=0.004]$ and $\mathrm{FMD}$ was also decreased in $\mathrm{SCH}$ with $\mathrm{TSH}<10 \mathrm{mIU} / \mathrm{I}[\mathrm{WMD}-1.794 \%$; $95 \% \mathrm{Cl}(-2.243,-1.345) ; \mathrm{p}<0.001]$ and heterogeneity was $\mathrm{I}^{2}=76.5 \%$. Subjects with $\mathrm{SCH}$ with $\mathrm{BMI} \geq 25 \mathrm{~kg} /$ $\mathrm{m}^{2}$ exhibited lower FMD [WMD - 2.229\%; 95\% Cl (-3.831, - 0.627); $\mathrm{p}=0.006]$ and decreased heterogeneity $\left(\mathrm{I}^{2}=58.5 \%, \mathrm{p}=0.064\right)$ versus $\mathrm{SCH}$ patients with $\mathrm{BMI}<25 \mathrm{~kg} / \mathrm{m}^{2}$ [WMD $-1.821 \% ; 95 \% \mathrm{Cl}(-2.300$, $-1.341)$; $\mathrm{p}<0.001]$ and a near heterogeneity $\left(\mathrm{I}^{2}=82.7 \%\right)$ than EU controls. We also conducted a subgroup analysis based on age groups. The FMD of WMD with $95 \% \mathrm{Cl}$ was [-1.820\%; (-2.281, -1.360$)$; $\mathrm{p}<0.001$ ] for SCH subjects aged $\leq 50$ to $<60$ yrs and a near heterogeneity $\left(I^{2}=78.4\right)$ and $[-1.836 \% ;(-2.318,-1.354) ; p<0.001]$ with decreased heterogeneity $\mathrm{I}^{2}=0.5 \%$ for subjects aged $\leq 30$ to $<40 \mathrm{yrs}$. However, there are no significant differences in subjects aged $\leq 40$ to $<50$ yrs [WMD $-2.845 \%$; $95 \% \mathrm{Cl}(-8.773,3.083) ; \mathrm{p}=0.347$ ] with $\mathrm{I}^{2}=94.3 \%$ and aged $<20$ yrs [WMD $-0.580 \% ; 95 \% \mathrm{Cl}(-2.438$, -1.278); $\mathrm{p}=0.541]$ compared with EU controls ( $\triangleright$ Table 4). 


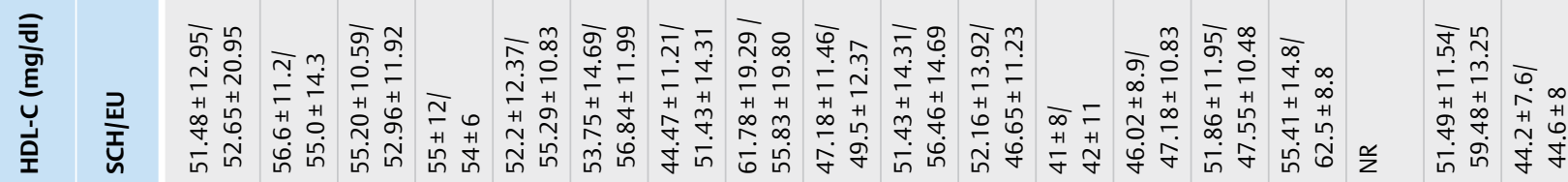

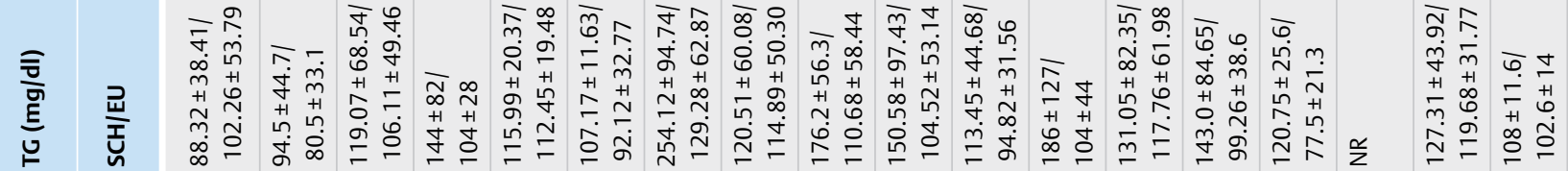

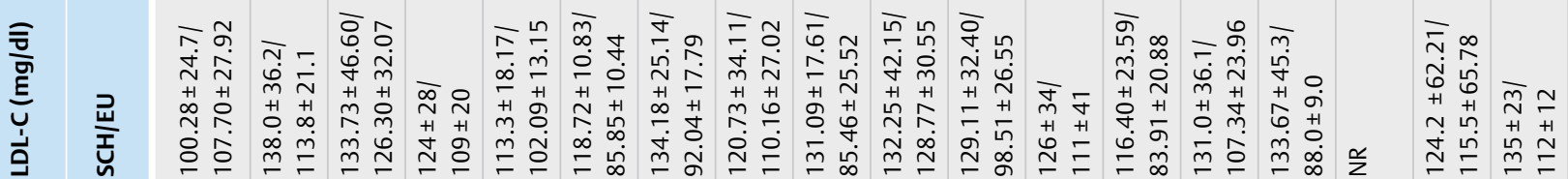

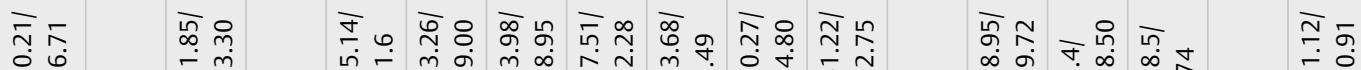

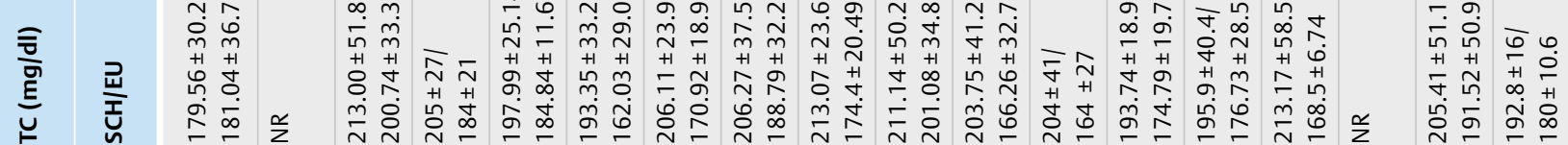

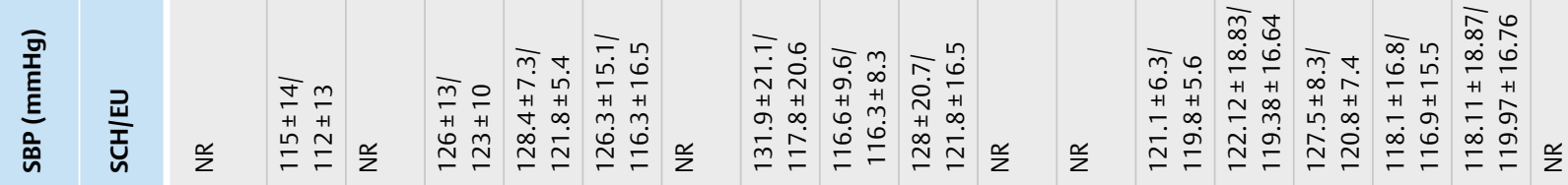

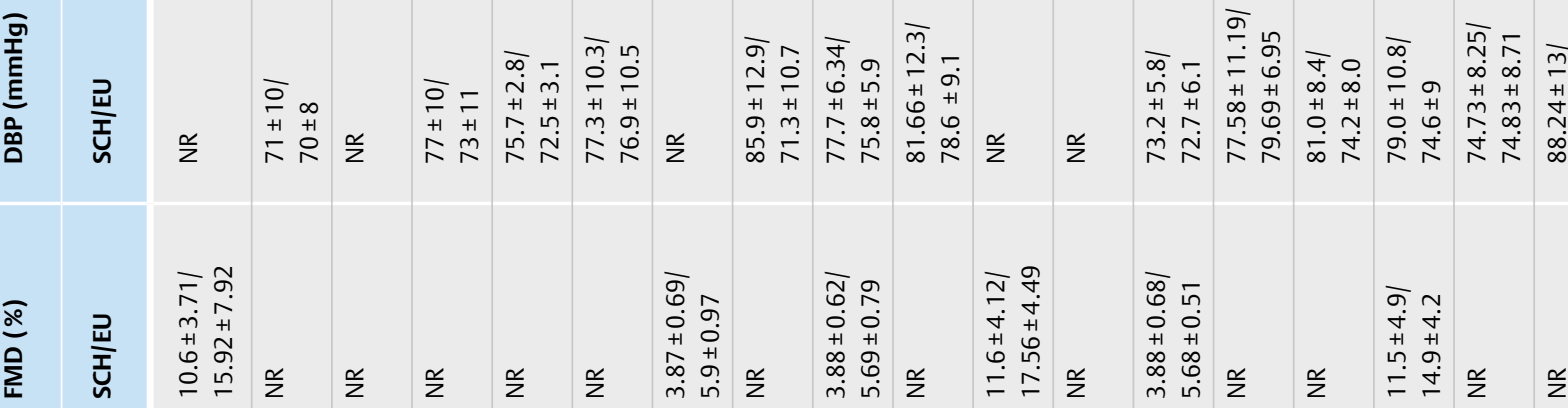

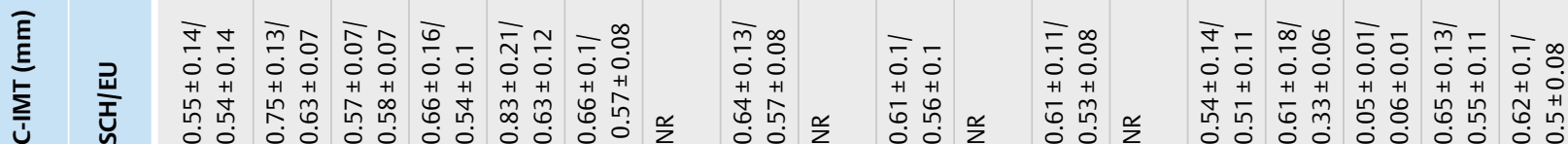

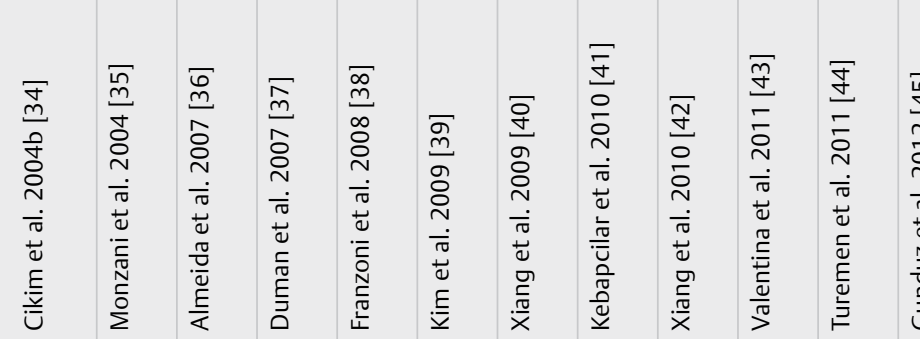

\begin{tabular}{|c|c|c|c|c|}
\hline 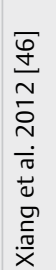 & 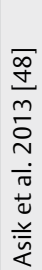 & 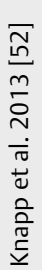 & 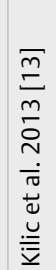 & 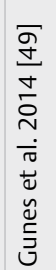 \\
\hline
\end{tabular}




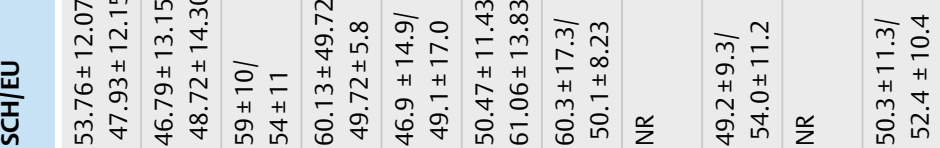

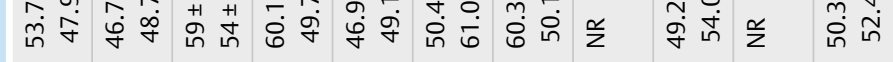

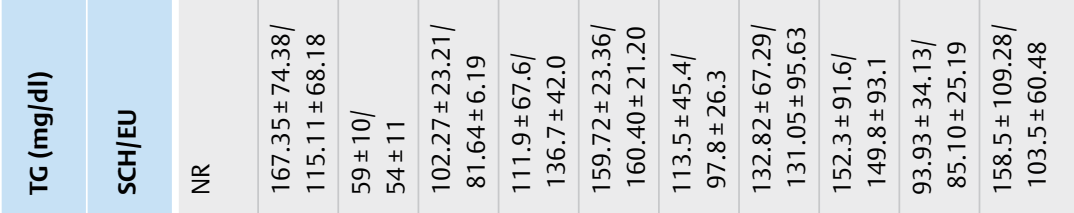

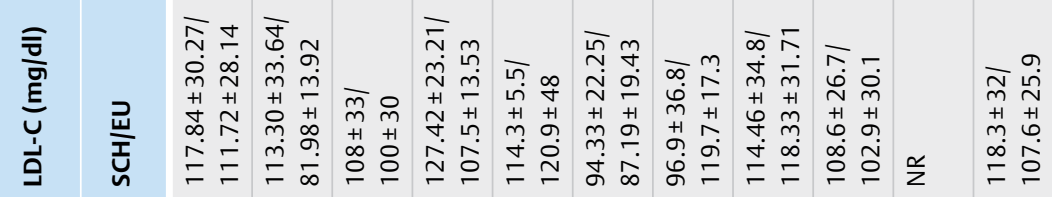

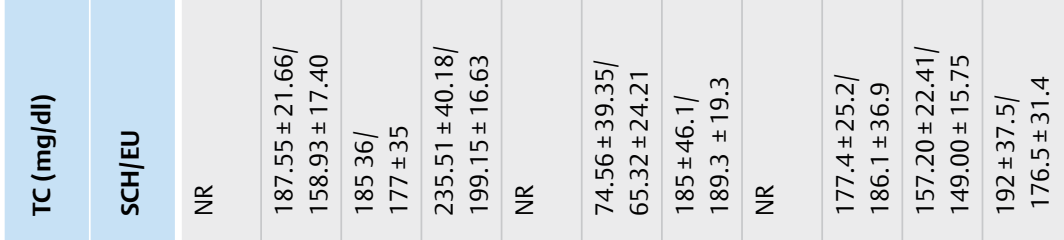

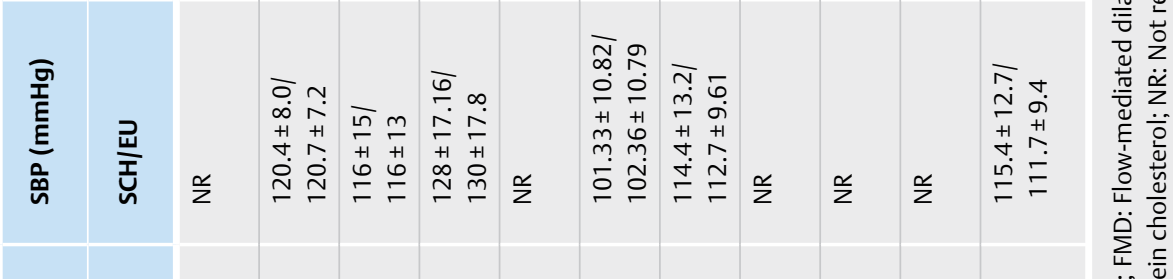

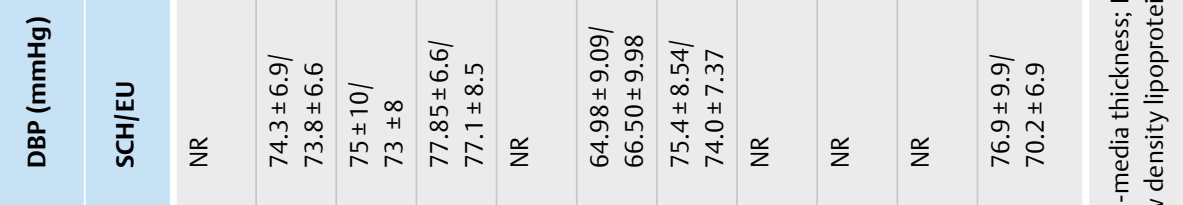

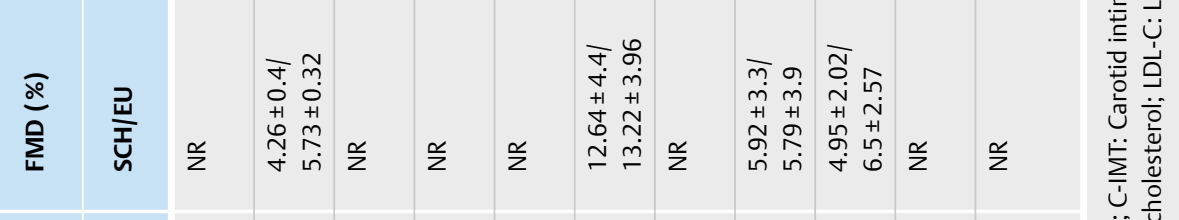

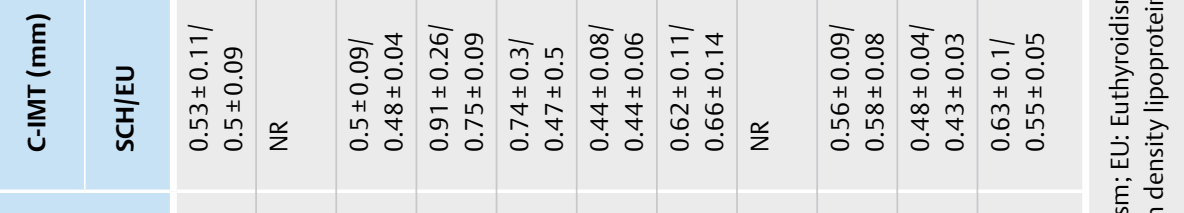

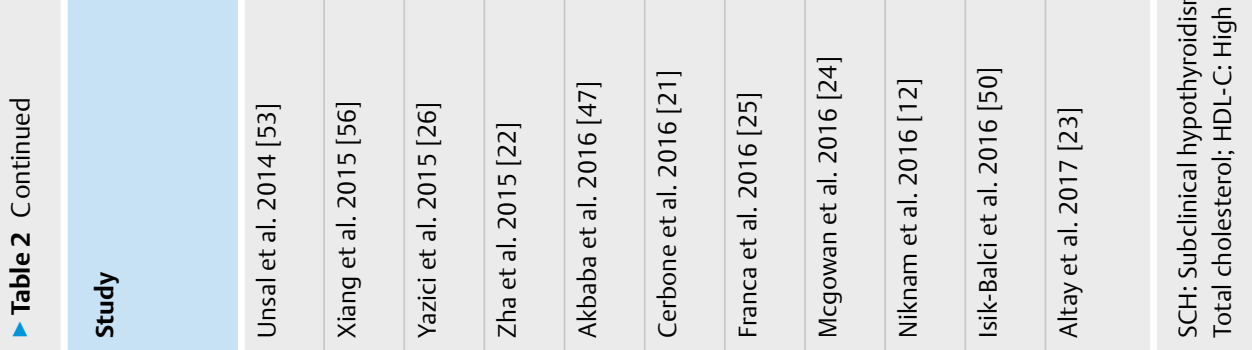


- Table 3 Subgroup analysis for C-IMT in SCH.

\begin{tabular}{|c|c|c|c|c|c|}
\hline & No. of studies & No. of patients & WMD $(95 \% \mathrm{Cl}) \mathrm{mm}$ & p-Value & $I^{2}(\%)$ \\
\hline Total & 23 & 1521 & $0.069 \mathrm{~mm}(0.042,0.095)$ & 0 & 93.1 \\
\hline Women $\geq 82 \%$ & 10 & 558 & $0.078 \mathrm{~mm}(0.034,0.122)$ & 0.001 & 88.8 \\
\hline Women $<82 \%$ & 13 & 963 & $0.061 \mathrm{~mm}(0.028,0.093)$ & 0 & 93.0 \\
\hline $\mathrm{TSH} \geq 10 \mathrm{mlU} / \mathrm{l}$ & 4 & 241 & $0.105 \mathrm{~mm}(-0.006,0.216)$ & 0.064 & 97.2 \\
\hline $\mathrm{TSH}<10 \mathrm{mIU} / \mathrm{l}$ & 19 & 1280 & $0.060 \mathrm{~mm}(0.036,0.084)$ & 0.000 & 81.1 \\
\hline $\mathrm{BMI} \geq 25 \mathrm{~kg} / \mathrm{m}^{2}$ & 14 & 865 & $0.041 \mathrm{~mm}(0.013,0.069)$ & 0.004 & 84.7 \\
\hline $\mathrm{BMI}<25 \mathrm{~kg} / \mathrm{m}^{2}$ & 6 & 376 & $0.145 \mathrm{~mm}(0.076,0.213)$ & 0 & 92.5 \\
\hline BMI (NR) & 3 & 280 & $0.050 \mathrm{~mm}(-0.023,0.122)$ & 0.178 & 92.2 \\
\hline Age $\leq 50$ to $<60 \mathrm{yrs}$ & 2 & 102 & $0.188 \mathrm{~mm}(0.122,0.253)$ & 0 & 0 \\
\hline Age $\leq 40$ to $<50$ yrs & 5 & 303 & $0.037 \mathrm{~mm}(-0.008,0.083)$ & 0.107 & 72.8 \\
\hline Age $\leq 30$ to $<40 \mathrm{yrs}$ & 14 & 954 & $0.078 \mathrm{~mm}(0.038,0.119)$ & 0 & 94.3 \\
\hline Age $<20$ yrs & 2 & 162 & $0.027 \mathrm{~mm}(-0.022,0.076)$ & 0.279 & 87.4 \\
\hline
\end{tabular}

\begin{tabular}{|c|c|c|c|}
\hline $\begin{array}{l}\text { Study } \\
\text { ID }\end{array}$ & & WMD (95\% Cl) & $\begin{array}{c}\% \\
\text { Weight }\end{array}$ \\
\hline cikim et al. (2004) & & $0.01(-0.07,0.09)$ & 3.67 \\
\hline Monzani et al. (2004) & $\rightarrow$ & $0.12(0.07,0.17)$ & 4.72 \\
\hline Almeida et al. (2007) & & $-0.01(-0.05,0.03)$ & 4.88 \\
\hline Duman et al. (2007) & $\rightarrow$ & $0.12(0.05,0.19)$ & 4.08 \\
\hline Franzoni et al. (2008) & $\longrightarrow$ & $0.20(0.12,0.28)$ & 3.74 \\
\hline Kim et al. (2009) & + & $0.09(0.05,0.13)$ & 4.79 \\
\hline Kebapcilar et al. (2010) & - & $0.07(0.02,0.12)$ & 4.43 \\
\hline Valentina et al. (2011) & $\rightarrow$ & $0.05(0.01,0.09)$ & 4.78 \\
\hline Gunduz et al. (2012) & $\longrightarrow$ & $0.08(0.02,0.14)$ & 4.14 \\
\hline Asik et al. (2013) & 5 & $0.03(-0.03,0.09)$ & 4.24 \\
\hline Knapp et al. (2013) & $\longrightarrow$ & $0.28(0.22,0.34)$ & 4.16 \\
\hline Kilic et al. (2013) & & $-0.01(-0.02,-0.00)$ & 5.46 \\
\hline Gunes et al. (2014) & $\leftarrow$ & $0.10(0.04,0.16)$ & 4.36 \\
\hline Karoli et al. (2014) & $\rightarrow$ & $0.12(0.08,0.16)$ & 4.98 \\
\hline Unsal et al. (2014) & - & $0.03(-0.01,0.07)$ & 4.90 \\
\hline Yazici et al. (2015) & - & $0.02(-0.01,0.05)$ & 5.10 \\
\hline Zha et al. (2015) & & $0.15(0.03,0.28)$ & 2.46 \\
\hline Akbaba et al. (2016) & & $0.27(0.10,0.44)$ & 1.67 \\
\hline Franca et al. (2016) & - & $-0.04(-0.13,0.05)$ & 3.38 \\
\hline Niknam et al. (2016) & & $-0.02(-0.07,0.03)$ & 4.66 \\
\hline Cerbone et al. (2016) & & $0.00(-0.03,0.03)$ & 5.08 \\
\hline Isik-Balci et al. (2016) & $\leftarrow$ & $0.05(0.03,0.07)$ & 5.38 \\
\hline Altay et al. (2017) & $\rightarrow$ & $0.08(0.04,0.12)$ & 4.93 \\
\hline Overall $(1-$ squared $=93.1 \%, p=0.000)$ & $\infty$ & $0.07(0.04,0.10)$ & 100.00 \\
\hline NOTE: Weights are from random effects analysis & & & \\
\hline-0.441 & & 0.441 & \\
\hline
\end{tabular}

- Fig. 2 WMD with $95 \% \mathrm{Cl}$ of C-IMT in SCH and EU subjects.

\section{Metabolic parameters changes in $\mathrm{SCH}$ and $\mathrm{EU}$ subjects}

As shown in — Table 5, the BMI [WMD $0.829 \mathrm{~kg} / \mathrm{m}^{2} ; 95 \% \mathrm{Cl}(0.457$, 1.200); $\mathrm{p}<0.001$ ] DBP [WMD $2.537 \mathrm{mmHg}$; $95 \% \mathrm{Cl}$ (1.171, 3.903); $\mathrm{p}<0.001$ ], SBP [WMD $2.401 \mathrm{mmHg} ; 95 \% \mathrm{Cl}(0.456,4.345)$; $\mathrm{p}=0.016$ ], TC [WMD $19.118 \mathrm{mg} / \mathrm{dl} ; 95 \% \mathrm{Cl}$ (13.734, 24.503); $\mathrm{p}<0.001]$, LDL-C [WMD $16.206 \mathrm{mg} / \mathrm{dl} ; 95 \% \mathrm{Cl}$ (10.336, 22.077); $\mathrm{p}<0.001$ ], and TG [WMD $20.917 \mathrm{mg} / \mathrm{dl} ; 95 \% \mathrm{Cl}$ (12.674, 29.159); $\mathrm{p}<0.001$ ] levels were significantly increased in $\mathrm{SCH}$ patients compared with control subjects, but the HDL-C [WMD $-1.224 \mathrm{mg} / \mathrm{dl}$; $95 \% \mathrm{Cl}(-3.020,0.573) ; \mathrm{p}=0.182$ ] level was not significantly different between the two groups. 


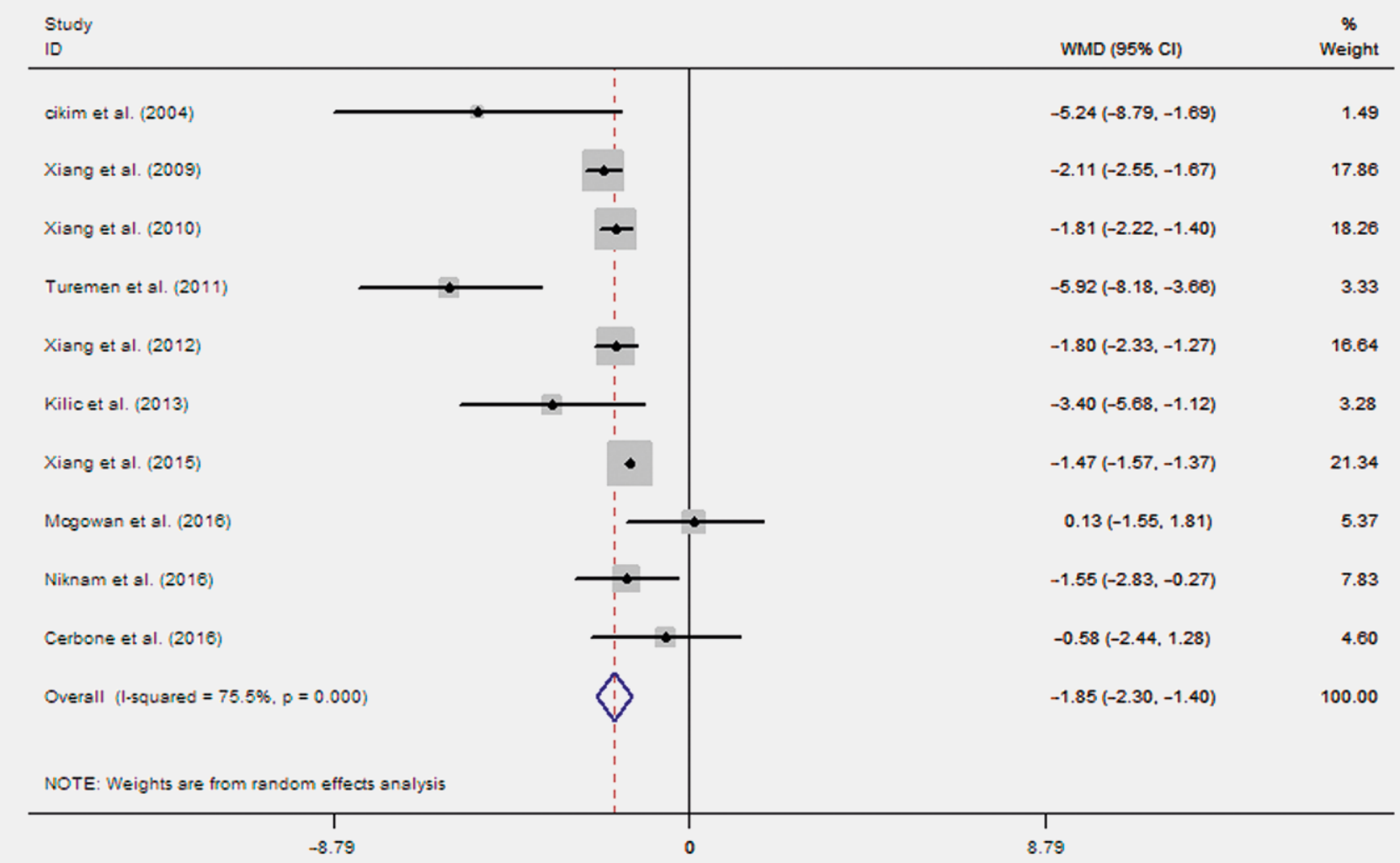

- Fig. 3 WMD with $95 \% \mathrm{Cl}$ of FMD in SCH and EU subjects.

- Table 4 Subgroup analysis for FMD in SCH.

\begin{tabular}{|c|c|c|c|c|c|}
\hline & No. of studies & No. of patients & WMD (95\% Cl) mm & p-Value & $I^{2}(\%)$ \\
\hline Total & 10 & 760 & $-1.848 \%(-2.298,-1.399)$ & 0 & 75.5 \\
\hline Women $\geq 82 \%$ & 5 & 439 & $-1.801 \%(-2.171,-1.431)$ & 0 & 73.2 \\
\hline Women $<82 \%$ & 5 & 321 & $-2.144 \%(-4.022,-0.267)$ & 0.025 & 81.4 \\
\hline $\mathrm{TSH} \geq 10 \mathrm{mlU} / \mathrm{l}$ & 1 & 61 & $-3.400 \%(-5.685,-1.115)$ & 0.004 & NR \\
\hline $\mathrm{TSH}<10 \mathrm{mIU} / \mathrm{l}$ & 9 & 699 & $-1.794 \%(-2.243,-1.345)$ & 0 & 76.5 \\
\hline $\mathrm{BMI} \geq 25 \mathrm{~kg} / \mathrm{m}^{2}$ & 4 & 237 & $-2.229 \%(-3.831,-0.627)$ & 0.006 & 58.5 \\
\hline $\mathrm{BMI}<25 \mathrm{~kg} / \mathrm{m}^{2}$ & 6 & 523 & $-1.821 \%(-2.300,-1.341)$ & 0 & 82.7 \\
\hline Age $\leq 50$ to $<60$ yrs & 4 & 419 & $-1.820 \%(-2.281,-1.360)$ & 0 & 78.4 \\
\hline Age $\leq 40$ to $<50$ yrs & 2 & 132 & $-2.845 \%(-8.773,3.083)$ & 0.347 & 94.3 \\
\hline Age $\leq 30$ to $<40 \mathrm{yrs}$ & 3 & 131 & $-1.836 \%(-2.318,-1.354)$ & 0 & 0.5 \\
\hline Age $<20$ yrs & 1 & 78 & $-0.580 \%(-2.438,-1.278)$ & 0.541 & NR \\
\hline
\end{tabular}

TSH: Thyroid-stimulating hormone; BMI: Body mass index; NR: Not reported

\section{Publication bias evaluation}

Egger's linear regression test used to examine publication bias indicated an absence of publication bias for FMD $(p=0.635)$ and a presence of publication bias for C-IMT $(p=0.045)$.

\section{Discussion}

In the current systematic review and meta-analysis of 29 clinical studies, it has been revealed that SCH might be correlated with endothelial dysfunction, which relates to the increase of C-IMT and the decrease of FMD. Patients with $\mathrm{SCH}$ were also associated with significantly increased BMI, DBP, SBP, TC, TG, and LDL-C. 
- Table 5 Metabolic parameters.

\begin{tabular}{|c|c|c|c|c|c|}
\hline Parameters & No. of studies & No. of patients & WMD $(95 \% \mathrm{Cl})$ & p-Value & $\mathrm{I}^{2}(\%)$ \\
\hline BMI $\left(\mathrm{kg} / \mathrm{m}^{2}\right)$ & 26 & 1771 & $0.829(0.457,1.200)$ & 0 & 38.3 \\
\hline $\mathrm{DBP}(\mathrm{mmHg})$ & 19 & 1391 & $2.537(1.171,3.903)$ & 0 & 55.5 \\
\hline SBP (mmHg) & 18 & 1291 & $2.401(0.456,4.345)$ & 0.016 & 51.8 \\
\hline TC (mg/dl) & 25 & 1715 & $19.118(13.734,24.503)$ & 0 & 76.2 \\
\hline LDL-C (mg/dl) & 27 & 1899 & $16.206(10.336,22.077)$ & 0 & 85.0 \\
\hline TG (mg/dl) & 27 & 1881 & $20.917(12.674,29.159)$ & 0 & 79.0 \\
\hline $\mathrm{HDL}-\mathrm{C}(\mathrm{mg} / \mathrm{dl})$ & 25 & 1718 & $-1.224(-3.020,0.573)$ & 0.182 & 53.1 \\
\hline
\end{tabular}

Some epidemiological studies have shown that the prevalence of $\mathrm{SCH}$ is higher in women [1]. Our subgroup analysis was conducted according to the proportion of women showing a higher C-IMT in $\mathrm{SCH}$ patients consisting of $\geq 82 \%$ women and a lower FMD in $\mathrm{SCH}$ patients consisting of $<82 \%$ women with a near heterogeneity. This result may indicate that gender is not associated with impairment of endothelial function in $\mathrm{SCH}$. Serum TSH concentration greater than $10 \mathrm{mIU} / \mathrm{I}$ is regarded as severe $\mathrm{SCH}$ [57]. Although C-IMT had no statistical difference in patients with $\mathrm{SCH}$ with $\mathrm{TSH} \geq 10.0 \mathrm{mIU} / \mathrm{I}$ compared with EU controls in our meta-analysis, C-IMT was significantly increased and FMD was significantly decreased in $\mathrm{SCH}$ with $\mathrm{TSH} \geq 10.0 \mathrm{mIU} / \mathrm{l}$ compared to $\mathrm{SCH}$ patients with $\mathrm{TSH}<10.0 \mathrm{mIU} / \mathrm{l}$. The studies of Gao et al. [27] with 7 higher-quality studies with 464 subjects have also demonstrated that C-IMT was higher in $\mathrm{SCH}$ patients with $\mathrm{TSH} \geq 10.0 \mathrm{mIU} / \mathrm{l}$. The 11 prospective cohort studies of Rodondi et al. [58] with 55287 patients have also demonstrated that higher TSH levels associated with the increased coronary heart disease events its mortality. This indicates that the severity of $\mathrm{SCH}$ is closely related to the degree of damage to endothelial function but other confounding factors cannot be ruled out (e. g., illness time, complications, and patient ages).

C-IMT and FMD are not other common indicators to evaluate endothelial function, but they can also predict the occurrence and development of CVD. The studies of van den Oord et al. [59] with 15 available articles have shown that C-IMT was associated with future stroke HR (hazard ratio) of 1.31 per 1-SD increased CIMT and HR of 1.17 per $0.1 \mathrm{~mm}$ increased C-IMT and was also associated with future myocardial infarction with $\mathrm{HR}$ of 1.26 per 1 -SD increase in C-IMT and HR of 1.15 per $0.1 \mathrm{~mm}$ increased in C-IMT. A meta-analysis including 14 cohort studies with 5547 participants has shown that $1 \%$ decrease and 1 -SD decrease in FMD was associated with $8 \%$ and $22 \%$ increase in risk of future cardiovascular events, respectively. It was illustrated that the vascular endothelium plays a critical role in various phases of the atherosclerotic disease process [16]. Another meta-analysis, which has indicated the overall CVD risk was 0.92 per $1 \%$ increased FMD and observed a significant decrease of FMD in diseased populations compared to asymptomatic populations. Furthermore, it was illustrated that decreased FMD is strongly related with future risk of CVD [60].
Obesity plays a key role in the development of CVD, and thus we also conducted a subgroup analysis with BMI values. Analysis results show that C-IMT was significantly increased in $\mathrm{SCH}$ with $\mathrm{BMI}<25 \mathrm{~kg} / \mathrm{m}^{2}$ patients compared with patients with $\mathrm{BMI} \geq 25 \mathrm{~kg} /$ $\mathrm{m}^{2}$ and the heterogeneity still high, but FMD was significantly decreased in $\mathrm{SCH}$ with $\mathrm{BMI} \geq 25 \mathrm{~kg} / \mathrm{m}^{2}$ and the heterogeneity was significantly reduced. We also performed subgroup analyses based on the patient's age. The C-IMT was significantly increased in SCH subjects aged $\leq 30$ to $<40 \mathrm{yrs}$ and $\leq 50$ to $<60 \mathrm{yrs}$ with decreased heterogeneity. The FMD was significantly decreased in $\mathrm{SCH}$ subjects aged $\leq 50$ to $<60$ yrs with a near heterogeneity and patients aged $\leq 30$ to $<40$ yrs with decreased heterogeneity. However, C-IMT and FMD were not significantly different in subjects aged $\leq 40$ to $<50$ yrs and $<20$ yrs compared with EU controls. This result suggests that the occurrence of $\mathrm{SCH}$ may be closely related to the people's age and the heterogeneity is associated with the level of BMl and patients age in patients with $\mathrm{SCH}$.

Hyperlipidemia is an important risk factor for CVD. Being consistent with our findings, meta-analysis of Liu et al. including 16 studies with 41931 adults has shown that TC, LDL-C, and TG levels were significantly increased and HDL-C level was not significantly different in SCH patients compared with EU individuals [61]. In addition, hypertension is strongly associated with endothelial function and C-IMT can predict the development of hypertension [62]. Noisy living environment contribute to the prevalence of hypertension [63]. In this meta-analysis, we also found that increased SBP and DBP were associated with SCH subjects. However, the DBP level was not significantly different in other meta-analysis [27]. This difference may be associated with the numbers of participants and the basic of characteristics.

Our meta-analysis has also some limitations. First, all of included studies were observational rather than randomized controlled trials. Thus, potential confounding factors may have affected the findings. Second, the detected methods for C-IMT or FMD are not entirely consistent and the definitions of $\mathrm{SCH}$ with serum TSH concentrations are different in different studies, and the results may not be generalizable to different populations. Third, although we were unable to identify its source by either meta-regression or subgroup analysis, there was some evidence of heterogeneity and pub- 
lic bias among the studies. The total sample size in this meta-analysis was relatively small, large clinical studies stratified by basic characteristics are essential.

\section{Conclusions}

Our meta-analysis has demonstrated that SCH patients are strongly related with endothelial dysfunction, hypertension, and hyperlipidemia. Higher level of TSH plays a key role in the development of those diseases. Large randomized controlled trial should be confirmed in SCH patients in different age levels and different TSH levels. The impact of L-T4 treatment and L-T4 dosages on these also should be explored. Further mechanisms should be investigated to explain the role of evaluated TSH in endothelial dysfunction with $\mathrm{SCH}$.

\section{Acknowledgements}

The authors wish to thank Liang Yao for his guidance and the staff of Lanzhou University of Evidence-Based Medicine Center for their assistance.

\section{Funding}

This work was supported by the National Natural Science Foundation of China (grant number: 81360125) and Gansu Province Natural Science Fund Project (grant number: 17JR5RA041).

\section{Conflict of Interest}

The authors declare that they have no conflict of interest.

\section{References}

[1] Canaris G], Manowitz NR, Mayor G et al. The Colorado thyroid disease prevalence study. Arch Intern Med 2000; 160: 526-534

[2] Vanderpump MP, Tunbridge WM, French JM et al. The incidence of thyroid disorders in the community: A twenty-year follow-up of the Whickham Survey. Clin Endocrinol (Oxf) 1995; 43: 55-68

[3] Hollowell JG, Staehling NW, Flanders WD et al. Serum TSH, T(4), and thyroid antibodies in the United States population (1988 to 1994): National Health and Nutrition Examination Survey (NHANES III). J Clin Endocrinol Metab 2002; 87: 489-499

[4] Ozturk S, Alcelik A, Ozyasar M et al. Evaluation of left ventricular systolic asynchrony in patients with subclinical hypothyroidism. Cardiol J 2012; 19: 374-380

[5] Hassan A, Altamirano-Ufion A, Zulfiqar B et al. Sub-clinical hypothyroidism and its association with increased cardiovascular mortality: Call for Action. Cardiol Res 2017; 8: 31-35

[6] Gencer B, Collet TH, Virgini V et al. Subclinical thyroid dysfunction and the risk of heart failure events: An individual participant data analysis from 6 prospective cohorts. Circulation 2012; 126: 1040-1049

[7] Chaker L, Baumgartner C, den Elzen WP et al. Subclinical hypothyroidism and the risk of stroke events and fatal stroke: An individual participant data analysis. J Clin Endocrinol Metab 2015; 100: 2181-2191

[8] Biondi B, Palmieri EA, Lombardi G et al. Effects of subclinical thyroid dysfunction on the heart. Ann Intern Med 2002; 137: 904-914
[9] Vargas-Uricoechea H, Bonelo-Perdomo A, Sierra-Torres CH. Effects of thyroid hormones on the heart. Clin Investig Arterioscler 2014; 26 : 296-309

[10] Ahirwar AK, Singh A, Jain A et al. Raised TSH is associated with endothelial dysfunction in Metabolic Syndrome: A case control study. Rom J Intern Med 2017; 55: 212-221

[11] Hendrani AD, Adesiyun T, Quispe R et al. Dyslipidemia management in primary prevention of cardiovascular disease: Current guidelines and strategies. World J Cardiol 2016; 8: 201-210

[12] Niknam N, Khalili N, Khosravi E et al. Endothelial dysfunction in patients with subclinical hypothyroidism and the effects of treatment with levothyroxine. Adv Biomed Res 2016; 538: 1-3

[13] Kilic ID, Tanriverdi H, Fenkci S et al. Noninvasive indicators of atherosclerosis in subclinical hypothyroidism. Indian J Endocrinol Metab 2013; 17: 271-275

[14] Staub D, Meyerhans A, Bundi B et al. Prediction of cardiovascular morbidity and mortality: Comparison of the internal carotid artery resistive index with the common carotid artery intima-media thickness. Stroke 2006; 37: 800-805

[15] Celermajer DS, Sorensen KE, Gooch VM et al. Non-invasive detection of endothelial dysfunction in children and adults at risk of atherosclerosis. Lancet 1992; 340: 1111-1115

[16] Inaba Y, Chen JA, Bergmann SR. Prediction of future cardiovascular outcomes by flow-mediated vasodilatation of brachial artery: A meta-analysis. Int J Cardiovasc Imaging 2010; 26: 631-640

[17] Peretz A, Leotta DF, Sullivan JH et al. Flow mediated dilation of the brachial artery: An investigation of methods requiring further standardization. BMC Cardiovasc Disord 2007; 711: 1-9

[18] Corretti MC, Anderson T], Benjamin EJ et al. Guidelines for the ultrasound assessment of endothelial-dependent flow-mediated vasodilation of the brachial artery: A report of the International Brachial Artery Reactivity Task Force. J Am Coll Cardiol 2002; 39: 257-265

[19] O'Leary DH, Polak JF. Intima-media thickness: A tool for atherosclerosis imaging and event prediction. Am J Cardiol 2002; 90: 18I-21I

[20] Lorenz MW, Markus HS, Bots ML et al. Prediction of clinical cardiovascular events with carotid intima-media thickness: a systematic review and meta-analysis. Circulation 2007; 115: 459-467

[21] Cerbone M, Capalbo D, Wasniewska M et al. Effects of L-thyroxine treatment on early markers of atherosclerotic disease in children with subclinical hypothyroidism. Eur J Endocrinol 2016; 175: 11-19

[22] Zha K, Zuo C, Wang A et al. LDL in patients with subclinical hypothyroidism shows increased lipid peroxidation. Lipids Health Dis 2015; 1495:

[23] Altay M, Karakoç MA, Çakır $N$ et al. Serum total sialic acid level is elevated in hypothyroid patients as an atherosclerotic risk factor. J Clin Lab Anal 2017; 31 doi:10.1002/jcla.22034 [Epub 2016 Jul 25]

[24] McGowan A, Widdowson WM, O'Regan A et al. Postprandial studies uncover differing effects on HDL particles of overt and subclinical hypothyroidism. Thyroid 2016; 26: 356-364

[25] Franca MM, Nogueira CR, Hueb JC et al. Higher carotid intima-media thickness in subclinical hypothyroidism associated with the metabolic syndrome. Metab Syndr Relat Disord 2016; 14: 381-385

[26] Yazici D, Ozben B, Toprak A et al. Effects of restoration of the euthyroid state on epicardial adipose tissue and carotid intima media thickness in subclinical hypothyroid patients. Endocrine 2015; 48: 909-915

[27] Gao N, Zhang W, Zhang YZ et al. Carotid intima-media thickness in patients with subclinical hypothyroidism: a meta-analysis. Atherosclerosis 2013; 227: 18-25

[28] Wells G, Brodsky L, O'Connell D et al. An evaluation of the Newcastle Ottawa Scale: An assessment tool for evaluating the quality of non-randomized studies [abstract]. XI Cochrane Colloquium: Evidence, Health Care and Culture 2003; Oct 26-31 Barcelona, Spain 2003 
[29] DerSimonian R, Laird N. Meta-analysis in clinical trials. Control Clin Trials 1986; 7: 177-188

[30] Higgins JP, Thompson SG, Deeks JJ et al. Measuring inconsistency in meta-analyses. BMJ 2003; 327: 557-560

[31] Egger M, Davey Smith G, Schneider M et al. Bias in meta-analysis detected by a simple, graphical test. BMJ 1997; 315: 629-634

[32] Unal E, Akın A, Yıldırım R et al. Association of subclinical hypothyroidism with dyslipidemia and increased carotid intima-media thickness in children. JCRPE J Clin Res Pediatr Endocrinol 2017; 9: 144-149

[33] Takashima N, Niwa Y, Mannami T et al. Characterization of subclinical thyroid dysfunction from cardiovascular and metabolic viewpoints The Suita study. Circulation J 2007; 71: 191-195

[34] Cikim AS, Oflaz H, Ozbey $\mathrm{N}$ et al. Evaluation of endothelial function in subclinical hypothyroidism and subclinical hyperthyroidism. Thyroid 2004; 14: 605-609

[35] Monzani F, Caraccio N, Kozàkowà M et al. Effect of levothyroxine replacement on lipid profile and intima-media thickness in subclinical hypothyroidism: A Double-blind, placebo-controlled study. J Clin Endocrinol Metab 2004; 89: 2099-2106

[36] Almeida CA, Teixeira Pde F, Soares DV et al. [Carotid intima-media thickness as a marker of cardiovascular risk in patients with subclinical hypothyroidism]. Arq Bras Endocrinol Metabol 2007; 51: 472-477

[37] Duman D, Demirtunc R, Sahin $S$ et al. The effects of simvastatin and levothyroxine on intima-media thickness of the carotid artery in female normolipemic patients with subclinical hypothyroidism: A prospective, randomized-controlled study. J Cardiovasc Med (Hagerstown) 2007; 8: 1007-1011

[38] Franzoni F, Galetta F, Fallahi P et al. Carotid integrated backscatter analysis in patients with subclinical hypothyroidism. Clin Endocrinol (Oxf) 2008; 68: 278-283

[39] Kim SK, Kim SH, Park KS et al. Regression of the increased common carotid artery-intima media thickness in subclinical hypothyroidism after thyroid hormone replacement. Endocr J 2009; 56: 753-758

[40] Xiang GD, Pu J, Sun $\mathrm{H}$ et al. Regular aerobic exercise training improves endothelium-dependent arterial dilation in patients with subclinical hypothyroidism. Eur J Endocrinol 2009; 161: 755-761

[41] Kebapcilar L, Comlekci A, Tuncel P et al. Effect of levothyroxine replacement therapy on paraoxonase- 1 and carotid intima-media thickness in subclinical hypothyroidism. Med Sci Monitor 2010; 16: CR41-CR47

[42] Xiang GD, Pu JH, Sun HL et al. Alpha-lipoic acid improves endothelial dysfunction in patients with subclinical hypothyroidism. Exp Clin Endocrinol Diabetes 2010; 118: 625-629

[43] Valentina VN, Marijan B, Chedo D et al. Subclinical hypothyroidism and risk to carotid atherosclerosis. Arq Bras Endocrinol Metabol 2011; 55 : $475-480$

[44] Turemen EE, Cetinarslan B, Sahin T et al. Endothelial dysfunction and low grade chronic inflammation in subclinical hypothyroidism due to autoimmune thyroiditis. Endocr J 2011; 58: 349-354

[45] Gunduz M, Gunduz E, Kircelli F et al. Role of surrogate markers of atherosclerosis in clinical and subclinical thyroidism. Int J Endocrinol 2012; 2012109797

[46] Xiang GD, Xiang LW, He HL et al. Postprandial lipaemia suppresses endothelium-dependent arterial dilation in patients with hypothyroidism. Endocrine 2012; 42: 391-398
[47] Akbaba G, Berker D, Isık S et al. Changes in the before and after thyroxine treatment levels of adipose tissue, leptin, and resistin in subclinical hypothyroid patients. Wien Klin Wochenschr 2016; 128: 579-585

[48] Aşik M, Sahin S, Ozkul F et al. Evaluation of epicardial fat tissue thickness in patients with Hashimoto thyroiditis. Clin Endocrinol 2013; 79: $571-576$

[49] Gunes F, Asik M, Temiz A et al. Serum H-FABP levels in patients with hypothyroidism. Wien Klin Wochenschr 2014; 126: 727-733

[50] Isik-Balci Y, Agladioglu S, Agladioglu K et al. Impaired hemorheological parameters and increased carotid intima-media thickness in children with subclinical hypothyroidism. Horm Res Paediatr 2016; 85: 250-256

[51] Karoli R, Fatima J, Shukla V et al. Hospital based study of carotid intima media thickness and high-sensitivity C-reactive protein in young hypothyroid patients. Indian Acad. Clin Med 2014; 15: 116-119

[52] Knapp M, Lisowska A, Sobkowicz B et al. Myocardial perfusion and intima-media thickness in patients with subclinical hypothyroidism. Adv Med Sci 2013; 58: 44-49

[53] Unsal IO, Topaloglu O, Colak NB et al. Effect of I-thyroxin therapy on thyroid volume and carotid artery intima-media thickness in patients with subclinical hypothyroidism. J Med Disord 2014; 2: 1

[54] Alibaz Oner F, Yurdakul S, Oner E et al. Evaluation of the effect of L-thyroxin therapy on endothelial functions in patients with subclinical hypothyroidism. Endocrine 2011; 40: 280-284

[55] Cerbone M, Capalbo D, Wasniewska M et al. Effects of L-thyroxine treatment on early markers of atherosclerotic disease in children with subclinical hypothyroidism. Eur J Endocrinol 2016; 175: 11-19

[56] Xiang G, Yue L, Zhang J et al. The relationship between circulating TRAIL and endothelial dysfunction in subclinical hypothyroidism. Endocrine 2015; 49: 184-190

[57] Gharib H, Tuttle RM, Baskin HJ et al. Subclinical thyroid dysfunction: a joint statement on management from the American Association of Clinical Endocrinologists, the American Thyroid Association, and the Endocrine Society. J Clin Endocrinol Metab 2005; 90: 581-585 discussion 586-587

[58] Rodondi N, den Elzen WP, Bauer DC et al. Subclinical hypothyroidism and the risk of coronary heart disease and mortality. JAMA 2010; 304: 1365-1374

[59] van den Oord SC, Sijbrands EJ, ten Kate GL et al. Carotid intima-media thickness for cardiovascular risk assessment: Systematic review and meta-analysis. Atherosclerosis 2013; 228: 1-11

[60] Ras RT, Streppel MT, Draijer R et al. Flow-mediated dilation and cardiovascular risk prediction: A systematic review with meta-analysis. Int J Cardiol 2013; 168: 344-351

[61] Liu XL, He S, Zhang SF et al. Alteration of lipid profile in subclinical hypothyroidism: A meta-analysis. Med Sci Monit 2014; 20: 1432-1441

[62] Takase H, Sugiura T, Murai S et al. Carotid intima-media thickness is a novel predictor of new onset of hypertension in normotensive subjects. Medicine (Baltimore) 2017; 96: e7710

[63] Huang D, Song X, Cui Q et al. Is there an association between aircraft noise exposure and the incidence of hypertension? A meta-analysis of 16784 participants. Noise Health 2015; 17: 93-97 